\title{
Benefits, Safety, and Adjunct Modality Prevalences of Long-Term Botulinum Toxin Injections for Cervical Dystonia and Myofascial Neck Pain: A Retrospective Cohort Study
}

This article was published in the following Dove Press journal:

Journal of Pain Research

\author{
Dion Diep (1) \\ Jasmine Ko $\mathbb{D}^{2}$ \\ John $\operatorname{Lan}^{3}$ \\ Kinga T Koprowicz $\left(\mathbb{D}^{3}\right.$ \\ Gordon Ko (D) ${ }^{3,4}$ \\ 'MD Program, University of Toronto, \\ Toronto, ON, Canada; ${ }^{2}$ Department of \\ Kinesiology, McMaster University, \\ Hamilton, ON, Canada; ${ }^{3}$ Canadian \\ Centre of Integrative Medicine, Toronto, \\ ON, Canada; ${ }^{4}$ Division of Physical \\ Medicine \& Rehabilitation, Sunnybrook \\ Health Sciences Centre, Toronto, ON, \\ Canada
}

Introduction: There is a paucity of long-term treatment benefit and safety data of botulinum toxin A (BTX-A) for cervical dystonia (CD) and myofascial neck pain syndrome (MPS). Additionally, the prevalence of adjunct modality uses during this period is unknown despite evolving practices.

Objective: To assess and compare treatment benefit, safety, and adjunct modality prevalences of long-term BTX-A injections between CD and MPS patients.

Design: Retrospective cohort study.

Setting: Private practice tertiary care clinics in Toronto.

Patients: Convenience sample of 37 (52.9\%) CD and 33 (47.1\%) MPS patients treated for a mean \pm SD duration of $7.2 \pm 4.3$ and $8.3 \pm 4.7$ years, respectively.

Interventions: BTX-A injections administered at least once yearly, for a duration longer than 1 year.

Main Outcome Measures: Toronto Western Spasmodic Torticollis Rating Scales (TWSTRS) for disability and pain, Patient Global Impression of Change (PGIC) score, time to peak effect, duration of total response, adverse effects, and prevalence of adjunct modalities.

Results: CD patients experienced improvements in TWSTRS disability (17.57 \pm 6.79 to 9.81 $\pm 4.35, \mathrm{p}<0.001)$ and pain $(14.61 \pm 3.08$ to $9.05 \pm 3.49, \mathrm{p}<0.001)$ scores as well as PGIC score $(52.00 \% \pm 23.60 \%$ to $64.80 \% \pm 23.60 \%, \mathrm{p}=0.007)$. MPS patients experienced improvements in TWSTRS disability $(15.86 \pm 7.70$ to $10.07 \pm 7.01, \mathrm{p}=0.01)$ and pain $(15.25 \pm 4.09$ to $10.85 \pm 4.49$, $\mathrm{p}=0.01$ ) scores. In both cohorts, there were no changes in time to peak effect and duration of total response. Adverse effects were minimal and self-limiting. Prevalences of adjunct modalities used by CD versus MPS patients were $28.13 \%$ versus $50.00 \%$ for anesthetic procedures, $23.08 \%$ versus $15.38 \%$ for image-guidance, $65.71 \%$ versus $56.25 \%$ for pectoralis minor injections, and $47.06 \%$ versus $53.13 \%$ for cannabis-use.

Conclusion: There were demonstrated and comparable treatment benefit, safety, and adjunct modality prevalences. Our study is the first to demonstrate that long-term BTX-A injections for MPS, although commonly used off-label, can be effective and safe.

Keywords: botulinum toxin, cervical dystonia, myofascial pain syndrome

\section{Plain Language Summary}

There is a paucity of long-term treatment benefit and safety data of botulinum toxin A (BTX-A) injections for treatment of cervical dystonia (CD) and myofascial neck pain (MPS). Additionally, evolving literature, guidelines, and legislations for the treatment of both conditions have resulted
Clinical Adjunct Lecturer, Division of Physical Medicine \& Rehabilitation, Sunnybrook Health Sciences Centre, 2075 Bayview Ave, Toronto, ON M4N

Tel $+|4| 6-480-4342$

Fax +|4|6-480-6885

Email drgordko@rogers.com
Journal of Pain Research 2020:13 1297-1304

1297

DovePress $f$ in $\mathbf{v}$

http://doi.org/10.2147/IPR.S254032 
in many concurrent treatment strategies to BTX-A injections, but it is unclear to what extent it is used in clinical practice. This includes pectoralis minor injections, cannabis-use, intravenous lidocaine with ketamine, radiofrequency ablation of the cervical facet joints, ultrasound-guidance, and electromyography guidance. We extracted data on all our CD and MPS patients who received BTX-A injections administered at least once yearly, for a duration longer than 1 year. We found that there were significant long-term improvements in pain and disability in both CD and MPS patients. However, only CD patients had significant improvements in their self reported improvement in overall health status. Adverse effects were minimal and self-limiting. The use of adjunct modalities was also considerable. In both cohorts, concurrent pectoralis minor injections and cannabis-use were the most common, followed by anesthetic procedures and image-guided injections.

\section{Introduction}

Botulinum toxin (BTX) is a neurotoxic protein produced by Clostridium botulinum known to interfere with synaptic transmission by inhibiting the release of acetylcholine (ACh). ${ }^{1}$ This mechanism would relax affected muscles and downstream effects could manifest as muscle weakness to muscle paralysis. ${ }^{1}$ C. botulinum is responsible for producing seven related toxins distinguishable by its antigenic properties. ${ }^{1}$ Most notably, there is substantial evidence to support the use of BTX type A (BTX-A) injections for treatment of cervical dystonia (CD) by virtue of its ability to relax spastic muscles. ${ }^{2}$ $\mathrm{CD}$ has been described elsewhere. ${ }^{2-4}$ A Cochrane Systematic Review (2017) of eight randomized-controlled trials ( $n=1010)$ found that BTX-A improved severity, disability, and pain after 8 to 20 weeks follow-up of a single injection compared to placebo. $^{5}$ In 2011 and 2016, respectively, the European Federation of Neurological Societies ${ }^{6}$ and the American Academy of Neurology, ${ }^{7}$ recommended BTX-A as first-line treatment for CD. Additionally, Health Canada has since approved BTX-A for first-line treatment of CD, of which there are currently available: OnaBTX-A (1995); IncoBTXA (2009); and AboBTX-A (2016). However, the long-term treatment benefit and safety of BTX-A are more uncertain as treatment durations are widely variable among studies. ${ }^{8-18}$ There is a paucity of studies with average treatment durations greater than a few years. ${ }^{12,14-16}$

Meanwhile, BTX-A injections are also commonly used off-label for myofascial neck pain syndrome (MPS). There are various theories on its mechanism of action, such as muscle relaxation secondary to reducing ACh-linked hyperactivity, inhibition of release of pain mediators, and reduction of pain sensitization. ${ }^{19}$ Despite this, the evidence supporting its use in the short to intermediate-term is contradictory as some trials ${ }^{20-23}$ and reviews ${ }^{24,25}$ demonstrate superiority over placebo while others do not. ${ }^{26-34}$ There remains even greater uncertainty with regards to its long-term safety and treatment benefit profile as there is limited long-term treatment or follow-up data.

Moreover, the management of CD and MPS is often multi-modal given the multifaceted and chronic nature of the patient's pain experience. The use of adjunct modalities, such as anesthetic interventions, ultrasound-guidance, electromyography (EMG)-guidance, pectoralis minor BTX-A injections, and cannabis-use are common alongside BTXA; however, the specific prevalence is unknown.

Therefore, the objective of our study was to present and compare treatment benefit, safety data, and adjunct modality prevalence following long-term treatment of BTX-A injections between patients with CD and MPS.

\section{Patients and Methods Study Design}

This retrospective cohort study was approved by the Sunnybrook Health Sciences Centre Research Ethics Board. We used a convenience sample of patients who were followed by neurology, pain medicine, and physiatry outpatient clinics at the Sunnybrook Health Sciences Centre and the Canadian Centre for Integrative Medicine in Toronto, Ontario.

\section{Participants}

Patients with injection data between August 2018 and August 2019 were screened for the following, a priori, inclusion criteria: 1) any sex of ages over 18 that received BTX-A injections (aboBTX-A, onaBTX-A, or incoBTX-A) for treatment of the primary diagnosis of CD or MPS, 2) treatment benefit, safety, or adjunct modality prevalence data available for their first and last injections, 3) treatment frequency of least once yearly between the first and last injections, 4) and total treatment duration of at least 1 year. CD was considered any sustained or intermittent muscle contractions of the neck, causing pain and abnormal repetitive movements, postures, or both. ${ }^{2-4}$ MPS was diagnosed according to the criteria of Simons and Travell (1999) with the major criteria for the diagnosis of MPS being 1) taut band palpable in an accessible muscle, 2) exquisite spot tenderness, 3) tightness of muscle causing restricted range of motion, and 4) localized pain to a region, usually unilateral. $^{35}$ Patients were excluded if their primary intervention was not BTX-A or if their primary injection sites 
were not restricted to the head, neck, or upper back (determined by relative frequency).

\section{Outcome Measurements}

The following outcomes were examined: clinical patient demographics and treatment variables (sex, age at first injection, age at last injection, total treatment period, total injections, mean dose per session), treatment benefit variables (injection units, patient global impression of change (PGIC) score out of $100 \%$, pain score (visual analogue scale out of 10 ), Toronto Western Spasmodic Torticollis Rating Scale (TWSTRS) disability score, TWSTRS pain score, time to peak effect, duration of total response), adverse events (dysphagia, ptosis, neck weakness, ocular side-effects, injection site weakness, noninjection site weakness, injection site hematoma, flu-like symptoms, hoarseness, generalized weakness, dry mouth, dysarthria), and adjunct modality prevalence (adjunct use of anesthetic interventions, ultrasound-guidance, EMGguidance, pectoralis minor BTX-A injections, and cannabisuse). The TWSTRS disability and pain subscales were used to compare patient-important outcomes between each cohort. Although only validated for CD patients, ${ }^{36}$ TWSTRS disability and pain subscales were used for MPS patients because, irrespective of etiology, the subscales can assess performances of daily activities and pain. ${ }^{37}$ All treatment benefit and safety data were obtained from routine-standardized patient intake forms completed before any immediate injection.

It is noteworthy that all included patients were treated sometime between 2001 and 2019. Literature, guidelines, and legislation have evolved throughout this period, which served as the rationale for our selection of the following adjunct modality variables of interest. Prevalence of adjuvant intravenous (IVC) lidocaine with ketamine, radiofrequency ablation of the cervical facet joints (medial sensory branches of the cervical dorsal rami), ultrasound-guidance, and EMG-guidance were examined given evidence showing improved outcomes in patients treated with BTX. ${ }^{38-41}$ Prevalence of adjuvant BTX-A pectoralis minor injections was examined because it is commonly used in practice to facilitate exercises for postural correction (eg, reducing anterior shoulder protraction and head forward posture). Finally, prevalence of cannabis-use was examined given the growing number of studies investigating its effects on dystonia. ${ }^{42-45}$ All our patients also began treatment when medical marijuana in Canada was legally permitted for off-label uses under the discretion of the prescribing physician. ${ }^{46}$

\section{Data Collection}

All data collected for patients were re-evaluated by two authors (DD, JK) for accuracy by assessing clinical records. Data were collected separately for CD and MPS cohorts. Before extracting any data, all relevant patient intake forms were de-identified by an administrative assistant such that no patient identifiers including name, date of birth, medical record number, and contact information were made aware to the authors. Patients were not directly contacted. Any data obtained were stored in a password-protected server that only the authors had access to. No additional information was collected other than what has been reported.

\section{Data Analysis}

Data extracted for patient and treatment-related variables, adjunct modality variables, and adverse effects were presented descriptively for CD and MPS cohorts. Nominal data were presented as counts and percentages, while numerical data were presented as means and standard deviations (SD). For adjunct modality prevalence, between-cohort comparisons were conducted using the Chi-square test. Data extracted for treatment benefit were analyzed by comparing first injection and last injection means (SDs) using the nonparametric Wilcoxon Rank-Sum Test. This test was selected given that Shapiro-Wilks tests revealed that our data were not normally distributed and that the analyzed variables were not independent. A $p<0.05$ was considered significant. Statistical analyses were performed using IBM SPSS version 23.0.

\section{Results}

\section{Cervical Dystonia}

\section{Patient Demographics and Treatment Variables}

Out of 645 individual patients who received any injections, a total of $39 \mathrm{CD}$ patients were treated with BTX-A injections for at least 1 year. Of these patients, 2 patients were excluded because they received BTX-A for under 1 year and 1 patient was excluded because they lacked treatment duration data. Information was extracted for 37 patients and included in the final analysis (Table 1). OnaBTX-A was the predominant drug formulation used $(91.90 \%, \mathrm{n}=34)$, followed by IncoBTX-A (5.41\%, n=2), and AboBTX-A (2.70\%, n=1). Patients were predominantly female $(75.68 \%, n=28)$ with a mean age of $53.76 \pm 13.97$ and $60.73 \pm 13.30$ at their first and last injections, respectively. The mean total treatment period was $7.17 \pm 4.31$ years. The mean total injections provided were $31.74 \pm 17.77$, with a mean dose of 186.47 \pm 133.82 per session. 
Table I Patient Demographics and Treatment Variables

\begin{tabular}{|l|l|l|l|l|}
\hline Variables & N & Cervical Dystonia & N & Myofascial Neck Pain Syndrome \\
\hline Sex & 37 & & 33 & \\
Male & & $\begin{array}{l}9(24.32 \%) \\
28(75.68 \%)\end{array}$ & & $12(36.36 \%)$ \\
Female & & $53.76(13.97)$ & $(63.64 \%)$ \\
\hline Age at first injection & 37 & $60.73(13.30)$ & 33 & $48.94(9.58)$ \\
Age at last injection & 37 & $7.17(4.31)$ & 33 & $57.12(10.16)$ \\
Total treatment period (years) & 36 & $31.74(17.77)$ & 29 & $8.25(4.66)$ \\
Total injections & 27 & $186.47(133.82)$ & 29 & $33.45(16.92)$ \\
Mean dose per session & 29 & 28 & $167.69(108.65)$ \\
\hline
\end{tabular}

\section{Treatment Benefit}

There were significant differences between first injection and last injection means (SD) for injection units (first injection: $186.47 \pm 133.82, \quad \mathrm{n}=29$; second injection: 258.82 $\pm 118.77, \mathrm{n}=36 ; \mathrm{p}=0.005$ ), PGIC score (first injection: $52.00 \pm 23.60, \mathrm{n}=28$; second injection: $64.80 \pm 23.60$, $\mathrm{n}=28 ; \mathrm{p}=0.007$ ), TWSTRS disability score (first injection: 17.57 $\pm 6.79, \mathrm{n}=21$; second injection: $9.81 \pm 4.35, \mathrm{n}=21$; $\mathrm{p}<0.001$ ), and TWSTRS pain score (first injection: 14.61 $\pm 3.08, \mathrm{n}=21$; second injection: 9.05 $\pm 3.49, \mathrm{n}=19$; $\mathrm{p}<0.001)$. Pain scores approached significance $(\mathrm{p}=0.09)$ between first injection scores $(6.63 \pm 2.07, \mathrm{n}=16)$ and last injection scores $(5.04 \pm 2.44, \mathrm{n}=14)$. No significant differences were found for time to peak effect and duration of total response (Table 2).

\section{Adverse Events}

Twenty-four patients had data available on adverse events, of which $16.67 \%(\mathrm{n}=4)$ patients reported any adverse event over the course of long-term treatment (Table 3). One patient reported ptosis, neck weakness, and flu-like symptoms; one patient reported dysphagia, dysarthria, hoarseness, and generalized weakness; one patient reported ptosis alone; and one patient reported neck weakness alone. The most common adverse effects were ptosis $(8.33 \%, n=2)$ and neck weakness $(8.33 \%, n=2)$. All cases of ptosis were due to BTX-A injections for the secondary diagnoses of chronic migraine $(8.33 \%, \mathrm{n}=2)$. All adverse events were self-limited; however, one patient required hospitalization for dysphagia. The average treatment period for these patients was 9.96 years.

Table 2 Treatment Benefit

\begin{tabular}{|c|c|c|c|c|c|}
\hline \multicolumn{6}{|l|}{ Cervical Dystonia } \\
\hline Variables & $\mathbf{N}$ & First Injection Mean (SD) & $\mathbf{N}$ & Last Injection Mean (SD) & Significance \\
\hline Injection units & 29 & I86.47 (|33.82) & 36 & $258.82(118.77)$ & 0.005 \\
\hline PGIC score & 28 & $52.00(23.60)$ & 28 & $64.80(23.60)$ & 0.007 \\
\hline Pain score & 16 & $6.63(2.07)$ & 14 & $5.036(2.44)$ & 0.09 \\
\hline TWSTRS disability & 21 & $17.57(6.79)$ & 21 & $9.81(4.35)$ & $<0.001$ \\
\hline TWSTRS pain & 21 & $|4.6|(3.08)$ & 19 & 9.05 (3.49) & $<0.001$ \\
\hline Time to peak effect (weeks) & 26 & $5.39(4.54)$ & 30 & $5.42(3.15)$ & 0.53 \\
\hline Duration of total response (weeks) & 26 & $9.00(4.10)$ & 28 & $9.80(3.13)$ & 0.27 \\
\hline \multicolumn{6}{|l|}{ Myofascial Neck Pain Syndrome } \\
\hline Variables & $\mathbf{N}$ & First Injection Mean (SD) & $\mathbf{N}$ & Last Injection Mean (SD) & Significance \\
\hline Injection units & 27 & $167.69(108.65)$ & 33 & $247.65(132.18)$ & 0.003 \\
\hline PGIC score & 27 & $59.60(29.80)$ & 26 & $59.60(22.50)$ & 0.72 \\
\hline Pain score & 13 & $6.50(2.13)$ & 11 & $6.00(2.05)$ & 0.72 \\
\hline TWSTRS disability & 14 & $15.86(7.70)$ & 14 & $10.07(7.01)$ & 0.01 \\
\hline TWSTRS pain & 14 & $15.25(4.09)$ & 13 & $10.85(4.49)$ & 0.01 \\
\hline Time to peak effect (weeks) & 29 & $4.57(2.61)$ & 29 & $5.20(3.03)$ & 0.25 \\
\hline Duration of total response (weeks) & 28 & $9.50(2.29)$ & 29 & $10.35(3.55)$ & 0.44 \\
\hline
\end{tabular}


Table 3 Adverse Events

\begin{tabular}{|c|c|c|}
\hline Variables & $\begin{array}{l}\text { Cervical } \\
\text { Dystonia } \\
(\mathrm{N}=24)\end{array}$ & $\begin{array}{l}\text { Myofascial Neck Pain } \\
\text { Syndrome }(\mathrm{N}=\mathbf{2 3})\end{array}$ \\
\hline Dysphagia & I (4.I7\%) & 0 \\
\hline Ptosis & 2 (8.33\%) & I (4.35\%) \\
\hline Neck weakness & 2 (8.33\%) & 0 \\
\hline Ocular side-effects & 0 & I (4.35\%) \\
\hline $\begin{array}{l}\text { Injection site } \\
\text { weakness }\end{array}$ & 0 & I (4.35\%) \\
\hline $\begin{array}{l}\text { Non-injection site } \\
\text { muscle weakness }\end{array}$ & 0 & 0 \\
\hline $\begin{array}{l}\text { Injection site } \\
\text { hematoma }\end{array}$ & 0 & 0 \\
\hline Flu-like symptoms & I (4.I7\%) & 0 \\
\hline Hoarseness & I (4.I7\%) & 0 \\
\hline $\begin{array}{l}\text { Generalized } \\
\text { weakness }\end{array}$ & I (4.I7\%) & 0 \\
\hline Dry mouth & 0 & 0 \\
\hline Dysarthria & I (4.I7\%) & 0 \\
\hline
\end{tabular}

\section{Adjunct Modality Prevalence}

Frequencies of adjunct anesthetic interventions were $12.50 \%$ $(\mathrm{n}=4)$ for IV lidocaine, $15.63 \%(\mathrm{n}=5)$ for radiofrequency denervation, $0 \%$ for both, and $71.88 \%(\mathrm{n}=23)$ for none. Frequencies of ultrasound-guidance, EMG-guidance, or neither were $3.85 \%(\mathrm{n}=1), 19.2 \% \quad(\mathrm{n}=5)$, and $76.92 \%$ $(\mathrm{n}=20)$, respectively. Adjunct pectoralis minor injections and cannabis-use frequencies were $65.71 \%(n=23)$ and $47.06 \%(n=16)$, respectively (Table 4$)$.

\section{Myofascial Neck Pain}

Patient Demographics and Treatment Variables

Out of 645 individual patients who received any injections, a total of 33 MPS patients were treated with BTX-A injections for at least 1 year. Information was extracted for 33 patients and included in the final analysis (Table 1). OnaBTX-A was the predominant drug formulation used $(90.91 \%, \mathrm{n}=30)$, followed by IncoBTX-A $(6.06 \%, \mathrm{n}=2)$, and AboBTX-A $(3.03 \%, \mathrm{n}=1)$. Patients were predominantly female $(63.64 \%, n=21)$ with a mean age of $48.94 \pm 9.58$ and $57.12 \pm 10.16$ at their first and last injections, respectively. The mean total treatment period was $8.25 \pm 4.66$ years. The mean total injections provided were $33.45 \pm 16.92$, with a mean dose of $167.69 \pm 108.65$ per session.

\section{Treatment Benefit}

There were significant differences between first injection and last injection means (SD) for injection units (first injection: $167.69 \pm 108.65, \mathrm{n}=27$; second injection: 247.65 $\pm 132.18, \mathrm{n}=33$; $\mathrm{p}=0.003$ ), TWSTRS disability score (first injection: $15.86 \pm 7.70, \mathrm{n}=14$; second injection: $10.07 \pm 7.01$, $\mathrm{n}=14 ; \mathrm{p}=0.01$ ), and TWSTRS pain score (first injection: 15.25 $\pm 4.09, \mathrm{n}=14$; second injection: $10.85 \pm 4.49, \mathrm{n}=13$; $\mathrm{p}=0.01$ ). No significant differences were found for PGIC scores, pain scores, time to peak effect, and duration of total response (Table 2).

\section{Adverse Events}

Twenty-three patients had data available on adverse events, of which $8.70 \%(\mathrm{n}=2)$ patients reported any adverse event

Table 4 Adjunct Modality Prevalence

\begin{tabular}{|c|c|c|c|c|}
\hline Variables & $\mathbf{N}$ & Cervical Dystonia & $\mathbf{N}$ & Myofascial Neck Pain Syndrome \\
\hline $\begin{array}{l}\text { Anesthetic } \\
\text { Intravenous lidocaine } \\
\text { Radiofrequency denervation } \\
\text { Both } \\
\text { None }\end{array}$ & 32 & $\begin{array}{l}4(12.50 \%) \\
5(15.63 \%) \\
0 \\
23(71.88 \%)\end{array}$ & 28 & $\begin{array}{l}8(28.57 \%) \\
4(14.29 \%) \\
2(7.14 \%) \\
14(50.00 \%)\end{array}$ \\
\hline $\begin{array}{l}\text { Imaging } \\
\text { Ultrasound-guidance } \\
\text { EMG-guidance } \\
\text { None }\end{array}$ & 26 & $\begin{array}{l}\text { I (3.85\%) } \\
5(19.23 \%) \\
20(76.92 \%)\end{array}$ & 26 & $\begin{array}{l}0 \\
4(15.38 \%) \\
22(84.62 \%)\end{array}$ \\
\hline $\begin{array}{l}\text { Pectoralis minor injection } \\
\text { No } \\
\text { Yes }\end{array}$ & 35 & $\begin{array}{l}12(34.29 \%) \\
23(65.71 \%)\end{array}$ & 32 & $\begin{array}{l}14(43.75 \%) \\
18(56.25 \%)\end{array}$ \\
\hline $\begin{array}{l}\text { Cannabis-use } \\
\text { No } \\
\text { Yes }\end{array}$ & 34 & $\begin{array}{l}18(52.94 \%) \\
16(47.06 \%)\end{array}$ & 32 & $\begin{array}{l}15(46.88 \%) \\
17(53.13 \%)\end{array}$ \\
\hline
\end{tabular}

Note: Chi-square analysis revealed no associations between each cohort and any adjunct modality variables. 
over the course of long-term treatment (Table 3). One patient reported injection site pain. Another patient reported ptosis and ocular side effects, which were due to BTX-A injections for the secondary diagnoses of blepharospasms $(4.35 \%$, $\mathrm{n}=1$ ). All adverse events were self-limited. The average treatment period for these patients was 8.83 years.

\section{Adjunct Modality Prevalence}

Frequencies of adjunct anesthetic interventions were $28.57 \%(n=8)$ for IV lidocaine, $14.29 \%(n=4)$ for radiofrequency denervation, $7.14 \%(\mathrm{n}=2)$ for both, and $50.00 \%$ $(\mathrm{n}=16)$ for none. Frequencies of ultrasound-guidance, EMG-guidance, or neither were $0 \%, 15.38 \%(\mathrm{n}=4)$, and $84.62 \%(\mathrm{n}=22)$, respectively. Adjunct pectoralis minor injections and cannabis-use frequencies were 56.25\% $(\mathrm{n}=18)$ and $53.13 \%(\mathrm{n}=17)$, respectively. Chi-square analysis revealed no associations between each cohort and any adjunct modality variables (Table 4 ).

\section{Discussion}

BTX-A is a first-line treatment for CD and commonly used off-label for MPS. Treatment benefit and long-term safety evidence can be used to better counsel patients about their potential long-term outcomes with BTX-A use. Meanwhile, clarifying the prevalence of adjunct anesthetic interventions, ultrasound-guidance, EMG-guidance, pectoralis minor injections, and cannabis-use can be used to inform future management by better characterizing both patient populations. New prevalence data can also be used to inform future research exploring the relationship between adjunct modality variables and its effect on the treatment benefit and safety of BTX-A.

The present study is the first to examine the long-term treatment benefit and safety of BTX-A for off-label use (eg, MPS) and to subsequently compare it to on-label use (eg, CD). It is also the first to examine the prevalence of modalities (eg anesthesia, ultrasound-guidance, EMGguidance, pectoralis minor injections, and cannabis-use) used adjunct with long-term BTX-A. At their final injection, both cohorts had significant increases in injection units, as well as improvements in the TWSTRS disability and pain scores. Only the CD cohort had a significant improvement in PGIC score. Both cohorts had no significant changes with respect to pain scores, time to peak effect, and duration of total effect. Adverse effects were minimal and self-limiting despite the long duration of BTX-A use. There was also considerable adjunct modality use. In both cohorts, concurrent pectoralis minor injections and cannabis-use were the most common, followed by anesthetic procedures and image-guided injections. Furthermore, all but two patients were still receiving ongoing BTX-A injections at the time of our study. Treatment was discontinued due to either adverse events or lack of effectiveness. A priori sensitivity analyses were conducted to assess the potential impact of patient discontinuation as well as different BTX-A formulations on the results, but no significant changes were found.

For CD patients, demographic and treatment-related variables were largely comparable to past cohorts with respect to sex and patient age at each injection. ${ }^{8-18}$ Generally, we had a longer mean treatment period ( 7.17 years) and greater mean cumulative dosage (7622 units) compared to previous studies. ${ }^{8,9,11,13,16}$ A significant increase found between first and last injection doses were in agreement with previous studies and can be partly attributed to conservative doses used in the beginning of treatment as well as the need for higher doses as the natural history of the disease progresses. ${ }^{10,12,14,15}$ The significant improvements in PGIC score and TWSTRS disability and pain score were also consistent with previous findings. ${ }^{8,9,12,14,15,17,18}$ However, we did not find significant improvements as expected in pain scores, time to peak effect, and duration of total response. Despite being a different disease entity, there were similar findings for our MPS cohort, except there was no significant improvement in PGIC score. This may be partly explained by the various comorbidities unique to this cohort, such as fibromyalgia, which may have confounded their global impression of change. Similar to previous findings, adverse effects were infrequent and tolerable in both cohorts. ${ }^{8-15,17,18}$

There are certain limitations of our study inherent to the nature of study design and patient population. First, it is retrospective design prone to missing, incorrect, and incomplete data. Despite having two investigators re-evaluate and search for any conflicting or missing data, outcomes of interest were still often powered by less than the number of total eligible patients. This imprecision is reflected by the large standard deviations present in our data. Additionally, we were unable to assess the change in prevalence of adjunct modalities due to incomplete records. Moreover, we were unable to control for confounding factors as our MPS cohort was clinically heterogenous. Patients often presented with comorbidities such as fibromyalgia, chronic migraine, and neuropathic pain.

\section{Conclusion}

There were demonstrated and comparable treatment benefit, safety, and adjunct modality prevalences of long-term 
BTX-A injections for CD and MPS. Our study is the first to demonstrate that long-term BTX-A injections for MPS, although commonly used off-label, can be effective and safe. Prevalence data of adjunct modalities can be used to inform future management and research as it relates to long-term treatment benefit and safety.

\section{Data Sharing Statement}

The data that support the findings of our study are available from the corresponding author upon reasonable request.

\section{Author Contributions}

All authors made substantial contributions to conception and design, acquisition of data, or analysis and interpretation of data; took part in drafting the article or revising it critically for important intellectual content; gave final approval of the version to be published; and agree to be accountable for all aspects of the work.

\section{Funding}

This study received a publication grant from Allergan Canada. The sponsor had no role in any stage from study design to submission of the paper for publication.

\section{Disclosure}

Dr. Gordon Ko has received speaker's and advisory board honoraria in the past from Allergan, Ipsen and Merz. The authors declare no other conflicts of interest in this work.

\section{References}

1. Nigam PK, Nigam A. Botulinum toxin. Indian J Dermatol. 2010;55 (1):8-14. doi:10.4103/0019-5154.60343

2. Galvez-Jimenez N, Lampuri C, Patino-Picirrillo R, Hargreave MJ, Hanson MR. Dystonia and headaches: clinical features and response to botulinum toxin therapy. Adv Neurol. 2004;94:321-328.

3. Chan J, Brin MF, Fahn S. Idiopathic cervical dystonia: clinical characteristics. Mov Disord. 1991;6(2):119-126. doi:10.1002/ mds. 870060206

4. Jahanshahi M, Marion MH, Marsden CD. Natural history of adult-onset idiopathic torticollis. Arch Neurol. 1990;47(5):548-552. doi:10.1001/archneur.1990.00530050070014

5. Castelao M, Marques RE, Duarte GS, et al. Botulinum toxin type A therapy for cervical dystonia. Cochrane Database Syst Rev. 2017;12:CD003633.

6. Albanese A, Asmus F, Bhatia KP, et al. EFNS guidelines on diagnosis and treatment of primary dystonias. Eur $J$ Neurol. 2011;18(1):5-18. doi:10.1111/j.1468-1331.2010.03042.x

7. Simpson DM, Hallett M, Ashman EJ, et al. Practice guideline update summary: botulinum neurotoxin for the treatment of blepharospasm, cervical dystonia, adult spasticity, and headache: report of the guideline development subcommittee of the American Academy of Neurology. Neurology. 2016;86(19):1818-1826. doi:10.1212/WN L. 0000000000002560
8. Dressler D, Paus S, Seitzinger A, Gebhardt B, Kupsch A. Long-term efficacy and safety of incobotulinumtoxinA injections in patients with cervical dystonia. J Neurol Neurosurg Psychiatry. 2013;84 (9):1014-1019. doi:10.1136/jnnp-2012-303608

9. Haussermann P, Marczoch S, Klinger C, Landgrebe M, Conrad B, Ceballos-Baumann A. Long-term follow-up of cervical dystonia patients treated with botulinum toxin A. Mov Disord. 2004;19 (3):303-308. doi:10.1002/mds.10659

10. Hsiung GY, Das SK, Ranawaya R, Lafontaine AL, Suchowersky O. Long-term efficacy of botulinum toxin A in treatment of various movement disorders over a 10-year period. Mov Disord. 2002;17 (6):1288-1293. doi:10.1002/mds.10252

11. Kessler KR, Skutta M, Benecke R. Long-term treatment of cervical dystonia with botulinum toxin A: efficacy, safety, and antibody frequency. German Dystonia Study Group. J Neurol. 1999;246 (4):265-274. doi:10.1007/s004150050345

12. Mejia NI, Vuong KD, Jankovic J. Long-term botulinum toxin efficacy, safety, and immunogenicity. Mov Disord. 2005;20(5):592-597. doi: $10.1002 / \mathrm{mds} .20376$

13. Mohammadi B, Buhr N, Bigalke H, Krampfl K, Dengler R, Kollewe K. A long-term follow-up of botulinum toxin A in cervical dystonia. Neurol Res. 2009;31(5):463-466. doi:10.1179/174313209X405137

14. Ramirez-Castaneda J, Jankovic J. Long-term efficacy and safety of botulinum toxin injections in dystonia. Toxins (Basel). 2013;5 (2):249-266. doi:10.3390/toxins5020249

15. Ramirez-Castaneda J, Jankovic J. Long-term efficacy, safety, and side effect profile of botulinum toxin in dystonia: a 20-year follow-up. Toxicon. 2014;90:344-348. doi:10.1016/j.toxicon.2014.07.009

16. Skogseid IM, Kerty E. The course of cervical dystonia and patient satisfaction with long-term botulinum toxin A treatment. Eur J Neurol. 2005;12(3):163-170. doi:10.1111/j.1468-1331.2004.01053.x

17. Trosch RM, Espay AJ, Truong D, et al. Multicenter observational study of abobotulinumtoxinA neurotoxin in cervical dystonia: the ANCHOR-CD registry. J Neurol Sci. 2017;376:84-90. doi:10.1016/ j.jns.2017.02.042

18. Truong D, Brodsky M, Lew M, et al. Long-term efficacy and safety of botulinum toxin type A (Dysport) in cervical dystonia. Parkinsonism Relat Disord. 2010;16(5):316-323. doi:10.1016/j.parkreldis.2010.03.002

19. Climent JM, Kuan TS, Fenollosa P, Martin-Del-Rosario F. Botulinum toxin for the treatment of myofascial pain syndromes involving the neck and back: a review from a clinical perspective. Evid Based Complement Alternat Med. 2013;2013:381459. doi:10.1155/2013/381459

20. Foster L, Clapp L, Erickson M, Jabbari B. Botulinum toxin A and chronic low back pain: a randomized, double-blind study. Neurology. 2001;56(10):1290-1293. doi:10.1212/WNL.56.10.1290

21. Gobel H, Heinze A, Reichel G, Hefter H, Benecke R, Dysport myofascial pain study g. Efficacy and safety of a single botulinum type A toxin complex treatment (Dysport) for the relief of upper back myofascial pain syndrome: results from a randomized double-blind placebo-controlled multicentre study. Pain. 2006;125(1-2):82-88. doi:10.1016/j.pain.2006.05.001

22. Gul K, Onal SA. [Comparison of non-invasive and invasive techniques in the treatment of patients with myofascial pain syndrome]. Agri. 2009;21(3):104-112. Turkish.

23. Miller D, Richardson D, Eisa M, Bajwa RJ, Jabbari B. Botulinum neurotoxin-A for treatment of refractory neck pain: a randomized, double-blind study. Pain Med. 2009;10(6):1012-1017. doi:10.1111/ j.1526-4637.2009.00658.x

24. Ferreira JJ, Couto M, Costa J, Coelho M, Rosa MM, Sampaio C. [Botulinum toxin for the treatment of pain syndromes]. Acta Reumatol Port. 2006;31(1):49-62. Portugese.

25. Alejandra CP, Usón JJ, Carmona L. Systematic review: can botulinum toxin be recommended as treatment for pain in myofascial syndrome? Reumatol Clin. 2006;2(4):173-182. doi:10.1016/S1699258X(06)73043-1 
26. De Andres J, Adsuara VM, Palmisani S, Villanueva V, LopezAlarcon MD. A double-blind, controlled, randomized trial to evaluate the efficacy of botulinum toxin for the treatment of lumbar myofascial pain in humans. Reg Anesth Pain Med. 2010;35(3):255-260. doi:10.1097/AAP.0b013e3181d23241

27. Ferrante FM, Bearn L, Rothrock R, King L. Evidence against trigger point injection technique for the treatment of cervicothoracic myofascial pain with botulinum toxin type A. Anesthesiology. 2005;103 (2):377-383. doi:10.1097/00000542-200508000-00021

28. Ho KY, Tan KH. Botulinum toxin A for myofascial trigger point injection: a qualitative systematic review. Eur J Pain. 2007;11 (5):519-527. doi:10.1016/j.ejpain.2006.09.002

29. Kamanli A, Kaya A, Ardicoglu O, Ozgocmen S, Zengin FO, Bayik Y. Comparison of lidocaine injection, botulinum toxin injection, and dry needling to trigger points in myofascial pain syndrome. Rheumatol Int. 2005;25(8):604-611. doi:10.1007/s00296-004-0485-6

30. Langevin P, Peloso PM, Lowcock J, et al. Botulinum toxin for subacute/chronic neck pain. Cochrane Database Syst Rev. 2011;7: CD008626.

31. Naumann M, So Y, Argoff CE, et al. Assessment: botulinum neurotoxin in the treatment of autonomic disorders and pain (an evidence-based review): report of the Therapeutics and Technology Assessment Subcommittee of the American Academy of Neurology. Neurology. 2008;70(19):1707-1714. doi:10.1212/01.wnl.000031 1390.87642.d8

32. Ojala T, Arokoski JP, Partanen J. The effect of small doses of botulinum toxin a on neck-shoulder myofascial pain syndrome: a double-blind, randomized, and controlled crossover trial. Clin J Pain. 2006;22(1):90-96. doi:10.1097/01.ajp.0000151871.51406.c3

33. Qerama E, Fuglsang-Frederiksen A, Kasch H, Bach FW, Jensen TS. A double-blind, controlled study of botulinum toxin A in chronic myofascial pain. Neurology. 2006;67(2):241-245. doi:10.1212/01. wn1.0000224731.06168.df

34. Waseem Z, Boulias C, Gordon A, Ismail F, Sheean G, Furlan AD. Botulinum toxin injections for low-back pain and sciatica. Cochrane Database Syst Rev. 2011;1:CD008257.
35. Travell JG, Simons DG. Myofascial Pain and Dysfunction: The Trigger Point Manual. Vol. 2. Baltimore: Williams \& Wilkins; 1999.

36. Consky ES, Basinski A, Belle L, Ranawaya R, Lang AE. The Toronto Western Spasmodic Torticollis Rating Scale (TWSTRS): assessment of validity and inter-rater reliability. Neurology. 1990;40:445. doi:10.1212/wnl.40.11.1743

37. Jost WH, Hefter H, Stenner A, Reichel G. Rating scales for cervical dystonia: a critical evaluation of tools for outcome assessment of botulinum toxin therapy. J Neural Transm (Vienna). 2013;120 (3):487-496. doi:10.1007/s00702-012-0887-7

38. Castagna A, Albanese A. Management of cervical dystonia with botulinum neurotoxins and EMG/ultrasound guidance. Neurol Clin Pract. 2019;9(1):64-73. doi:10.1212/CPJ.0000000000000568

39. Cloud LJ, Jinnah HA. Treatment strategies for dystonia. Expert Opin Pharmacother. 2010;11(1):5-15. doi:10.1517/14656560903426171

40. Contarino MF, Van Den Dool J, Balash Y, et al. Clinical practice: evidence-based recommendations for the treatment of cervical dystonia with botulinum toxin. Front Neurol. 2017;8:35. doi:10.3389/ fneur.2017.00035

41. Kapural L, Mekhail N. Radiofrequency ablation for chronic pain control. Curr Pain Headache Rep. 2001;5(6):517-525. doi:10.1007/ s11916-001-0069-z

42. Chatterjee A, Almahrezi A, Ware M, Fitzcharles MA. A dramatic response to inhaled cannabis in a woman with central thalamic pain and dystonia. J Pain Symptom Manage. 2002;24(1):4-6. doi:10.1016/ S0885-3924(02)00426-8

43. Consroe P, Sandyk R, Snider SR. Open label evaluation of cannabidiol in dystonic movement disorders. Int $J$ Neurosci. 1986;30 (4):277-282. doi:10.3109/00207458608985678

44. Koppel BS. Cannabis in the treatment of dystonia, dyskinesias, and tics. Neurotherapeutics. 2015;12(4):788-792. doi:10.1007/s13311015-0376-4

45. Zadikof C, Wadia PM, Miyasaki J, et al. Cannabinoid, CB1 agonists in cervical dystonia: failure in a phase IIa randomized controlled trial. Basal Ganglia. 2011;1(2):91-95. doi:10.1016/j.baga.2011.04.002

46. Marihuana for medicinal purposes regulations. Justice Law Website: Government of Canada; 2001.
Journal of Pain Research

\section{Publish your work in this journal}

The Journal of Pain Research is an international, peer reviewed, open access, online journal that welcomes laboratory and clinical findings in the fields of pain research and the prevention and management of pain. Original research, reviews, symposium reports, hypothesis formation and commentaries are all considered for publication. The manuscript management system is completely online and includes a very quick and fair peer-review system, which is all easy to use. Visit http:// www.dovepress.com/testimonials.php to read real quotes from published authors. 